
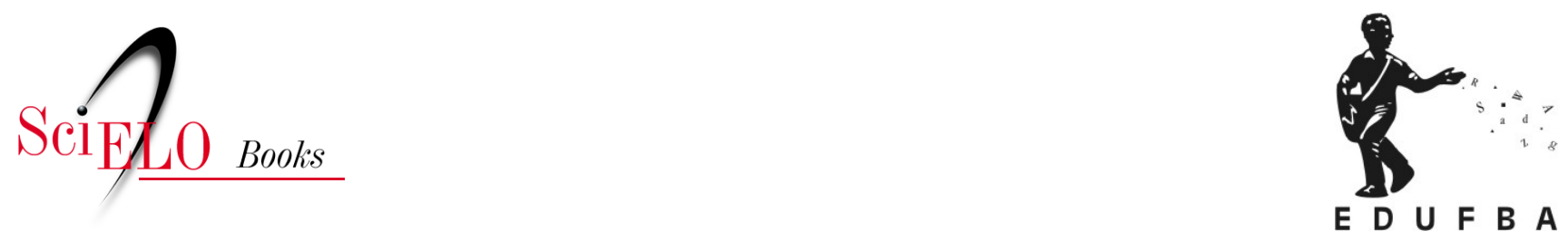

\title{
23 Tribo Neurolaeneae Rydb.
}

\author{
Nádia Roque
}

ROQUE, N. Tribo Neurolaeneae Rydb. In: ROQUE, N. TELES, A.M., and NAKAJIMA, J.N., comp. A familia Asteraceae no Brasil: classificação e diversidade [online]. Salvador: EDUFBA, 2017, pp. 171174. ISBN: 978-85-232-1999-4. https://doi.org/10.7476/9788523219994.0025.

All the contents of this work, except where otherwise noted, is licensed under a Creative Commons Attribution 4.0 International license.

Todo o conteúdo deste trabalho, exceto quando houver ressalva, é publicado sob a licença Creative Commons Atribição $\underline{4.0}$. 


\section{TRIBO NEUROLAENEAE RYDB.}

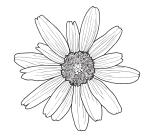

Nádia Roque

A partir dos estudos moleculares realizados por Panero e Funk (2002, 2008), Neurolaeneae foi elevada ao status de tribo e incluída na Aliança Heliantheae como grupo irmão de Bahieae, Chaenactideae e Tageteae. Atualmente, é circunscrita com 5 gêneros e cerca de 153 espécies, com a maioria representada nas áreas tropicais do México e América do Sul (PANERO, 2007).

A tribo caracteriza-se pelas flores do raio, se presentes, pistiladas, receptáculo geralmente paleáceo, anteras amarelas, cipselas enegrecidas e pápus geralmente de páleas ou escamas livres, raramente coroniforme ou ausente.

\section{Descrição}

Ervas, arbustos, raramente árvores, anuais ou perenes, monoicas. Folhas alternas ou opostas, raro verticiladas. Capitulescência paniculiforme ou corimbiforme ou capítulos terminais ou axilares, solitários em longos pedúnculos, discoides (Figura 17C) ou radiados; invólucro cilíndrico, campanulado ou hemisférico; brácteas involucrais em 1 a 8 séries, subiguais a graduadas; receptáculo plano a cônico (Figura 17D), geralmente paleáceo, páleas cartáceas. Flores do raio, quando presentes, pistiladas, corola liguliforme, amarela, raramente alva, conspícua ou algumas vezes pouco saliente às páleas; flores do disco bissexuais ou funcionalmente estaminadas, corola actinomorfa, (4-)5(-6) lobos, com canais de resina avermelhados ou alaranjados, amarela, raro alvo ou púrpura; anteras ecalcaradas, ecau- 
dadas, apêndice do conectivo deltado a ovalado, glandular abaxialmente; ramos do estilete agudos, papilosos. Cipselas obcônicas a obpiramidais, algumas vezes obcompressas, paredes carbonizadas, glabras a densamente pubescentes, algumas vezes com tricomas glandulares; pápus de cerdas, páleas ou escamas, subiguais ou desiguais, escamas algumas vezes fundidas na base, raramente coroniforme ou pápus ausente (Figura 17F).

No Brasil, a tribo está representada por 2 gêneros (Calea L. e Enydra Lour.) e cerca de 82 espécies distribuídas em todos os domínios fitogeográficos. Calea constitui mais de $80 \%$ da diversidade da tribo (BALDWIN, 2009), com cerca de 125 espécies e com distribuição neotropical, sendo que um grande número é registrado para o nordeste da América do Sul e Brasil (cerca de 80 spp.) (Figuras 18G-K) (PRUSKI; URBATSCH, 1988; WUSSOW; URBATSCH; SULLIVAN, 1985). Enydra apresenta 10 espécies pantropicais e, no Brasil, há registro de apenas 2, E. radicans (Willd.) Lack e E. anagallis Gardner com ampla distribuição.

\section{Chave de identificação para os gêneros de Neurolaeneae no Brasil}

1. Plantas terrestres; capítulos terminais, pedunculados; cipsela com pápus de escamas livres, raramente coroniforme com ápice eroso (Figura 17E) ..... .. Calea 1'. Plantas aquáticas ou de locais alagados; capítulos axilares, sésseis a subsésseis; cipsela com pápus coroniforme com ápice inteiro (Figura 17F) . Enydra

\section{Literatura recomendada}

BALDWIN, B. G. Heliantheae alliance. In: FUNK, V. A. et al. (Ed.). Systematics, Evolution and Biogeography of Compositae. Vienna: IAPT, 2009. Chapt. 41, p. 689-711. 
PANERO, J. L. Tribe Neurolaeneae Rydb. In: KADEREIT, J. W.; JEFFREY, C. (Ed.). The Families and Genera of Vascular Plant: v. VIII: Flowering Plants Eudicots: Asterales. Berlin: Springer, 2007. p. 417-420.

PANERO, J. L.; FUNK, V. A. The value of sampling anomalous taxa in phylogenetic studies: major clades of the Asteraceae revealed. Molecular Phylogenetics and Evolution, v. 47, p. 757-782, 2008.

PRUSKI, J. F. Calea brittoniana and Calea kristiniae: two new Compositae from Brazil. Brittonia, Bronx, v. 36, p. 98-103, 1984

PRUSKI, J. F. Novelties in Calea (Compositae: Heliantheae) from South America. Kew Bulletin, London, v. 53, n. 3, p. 683-693, 1998.

PRUSKI, J. F.; URBATSCH, L. E. Five new species of Calea (Compositae: Heliantheae) from Planaltine Brazil. Brittonia, London, v. 40, n. 4, p. 341-356, 1988.

PRUSKI, J. F.; HIND, D. J. N. Two new species of Calea (Compositae: Heliantheae) from Serra do Grão Mogol and vicinity, Minas Gerais, Brazil. Kew Bulletin, London, v. 53, n. 3, p. 695-701, 1998.

ROBINSON, H. Studies in the Heliantheae (Asteraceae). XIX. Four new species of Calea from Brazil. Phytologia, Huntsville, v. 44, p. 270-279, 1979a.

ROBINSON, H. Studies in the Heliantheae (Asteraceae). XXII. Two new species of Calea from Brazil. Phytologia, Huntsville, v. 44, p. 436-441, $1979 \mathrm{~b}$.

ROBINSON, H. Studies in the Heliantheae (Asteraceae). XXVII. A new species of Calea from Brazil. Phytologia, Huntsville, v. 47, 1980. p. 261-263. ROBINSON, H. Studies in the Heliantheae (Asteraceae). XXVIII. Additions to Calea and Ichthyothere from Brazil. Phytologia, Huntsville, v. 49, p. 10-13, 1981.

ROQUE, N.; CARVALHO, V. C. Estudos taxonômicos do gênero Calea (Asteraceae, Neurolaeneae) no estado da Bahia, Brasil. Rodriguésia, Rio de Janeiro, v. 62, n. 3, p. 547-561, 2011.

URBATSCH, L. E; ZLOTSKY, A.; PRUSKI, J. F. Revision of Calea sect. Lemmatium (Asteraceae: Heliantheae) from Brazil. Systematic Botany, Kent, v. 11, n. 4, p. 501-514, 1986. 
WUSSOW, J. R.; URBATSCH, L. E.; SULLIVAN, G. A. Calea (Asteraceae) in Mexico, Central America and Jamaica. Systematic Botany, Kent, v. 10, n. 3, p. 241-267, 1985. 